\title{
Characteristics of feed efficiency within and across lactation in dairy cows and the effect of genetic selection
}

\author{
A. M. Hurley, ${ }^{\dagger} \dagger$ N. Lopez-Villalobos, $†$ S. McParland, ${ }^{*}$ E. Lewis, ${ }^{*}$ E. Kennedy, ${ }^{*}$ M. O'Donovan, ${ }^{*}$ J. L. Burke, $\dagger$ \\ and D. P. Berry*1 \\ ${ }^{*}$ Teagasc, Animal \& Grassland Research and Innovation Center, Moorepark, Fermoy, Co. Cork, Ireland \\ †Institute of Veterinary, Animal and Biomedical Science, Massey University, Private Bag 11-222, Palmerston North 4442, New Zealand
}

\begin{abstract}
The objective of the present study was to investigate the phenotypic inter- and intra-relationships within and among alternative feed efficiency metrics across different stages of lactation and parities; the expected effect of genetic selection for feed efficiency on the resulting phenotypic lactation profiles was also quantified. A total of 8,199 net energy intake $\left(\mathrm{NE}_{\mathrm{I}}\right)$ test-day records from 2,505 lactations on 1,290 cows were used. Derived efficiency traits were either ratio based or residual based; the latter were derived from least squares regression models. Residual energy intake (REI) was defined as $\mathrm{NE}_{\mathrm{I}}$ minus predicted energy requirements based on lactation performance; residual energy production (REP) was defined as net energy for lactation minus predicted energy requirements based on lactation performance. Energy conversion efficiency was defined as net energy for lactation divided by $\mathrm{NE}_{\mathrm{I}}$. Pearson phenotypic correlations among traits were computed across lactation stages and parities, and the significance of the differences was determined using the Fisher r-to-z transformation. Sources of variation in the feed efficiency metrics were investigated using linear mixed models, which included the fixed effects of contemporary group, breed, parity, stage of lactation, and the 2-way interaction of parity by stage of lactation. With the exception of REI, parity was associated with all efficiency and production traits. Stage of lactation, as well as the 2-way interaction of parity by stage of lactation, were associated with all efficiency and production traits. Phenotypic correlations among the efficiency and production traits differed not only by stage of lactation but also by parity. For example, the strong phenotypic correlation between REI and en-
\end{abstract}

Received March 7, 2017.

Accepted October 3, 2017.

${ }^{1}$ Corresponding author: donagh.berry@teagasc.ie ergy balance (EB; 0.89) for cows in parity 3 or greater and early lactation was weaker for parity 1 cows at the same lactation stage (0.81), suggesting primiparous cows use the ingested energy for both milk production and growth. Nonetheless, these strong phenotypic correlations between REI and EB suggested negative REI animals (i.e., more efficient) are also in more negative EB. These correlations were further supported when assessing the effect on phenotypic performance of animals genetically divergent for feed intake and efficiency based on parental average. Animals genetically selected to have lower REI resulted in cows who consumed less $\mathrm{NE}_{\mathrm{I}}$ but were also in negative $\mathrm{EB}$ throughout the entire lactation. Nonetheless, such repercussions of negative EB do not imply that selection for negative REI (as defined here) should not be practiced, but instead should be undertaken within the framework of a balanced breeding objective, which includes traits such as reproduction and health.

Key words: estimated breeding value, feed intake, residual energy intake, energy balance, heritability

\section{INTRODUCTION}

Improving feed efficiency is a well-established goal in many species and is highly relevant given current international concerns regarding greenhouse gas emissions, nutrient losses, and water quality (Leip et al., 2015). Therefore, identifying more efficient animals that produce the same quantity of product using fewer resources is highly desirable. Feed efficiency in some species has improved substantially in recent decades although this trend has not been as rapid in other species, especially ruminants. The ratio of energy ingested versus energy output in usable product for dairy cows is much worse than both pigs and poultry (Havenstein et al., 1994; Losinger, 1998). Therefore, improving feed efficiency in ruminants is particularly important. It is also important to unravel the correlation structure of feed efficiency across the productive life of the cow and to understand the repercussions of genetic selection for the feed intake complex on the resulting lactation 
profiles of feed efficiency and related traits (e.g., energy balance; EB).

The contribution of breeding to improvements in feed efficiency is well recognized (Cahaner and Siegel, 1986; Havenstein et al., 1994, 2003). In poultry, the kilograms of feed required to produce a kilogram of meat (i.e., feed conversion ratio) was predicted to have decreased by $50 \%$ and growth rate increased by over $400 \%$, between the years 1960 and 2005 (Zuidhof et al., 2014). Also, in broilers, Sherwood (1977) and Havenstein et al. (2003) showed that approximately 85 to $90 \%$ of the improvements in feed efficiency are due to genetics. Although response to selection for a trait can be predicted using selection index theory (Smith, 1936), accurate predictions require a large population of phenotyped animals to accurately estimate the necessary genetic parameters. Nonetheless, in the absence of precise estimates of genetic parameters, especially the necessary genetic (co)variances, it is possible to elucidate the response to selection through examination of phenotypic performance of animals divergent in genetic merit for the trait of interest (which does not include their own phenotypic information). Such a strategy could be useful in lactating dairy cows where data to estimate precise genetic parameters are limited.

The focus of the present study was, therefore, to accurately quantify the phenotypic inter- and intra-relationships among alternative feed efficiency metrics and other performance traits across parities and lactation stages in lactating dairy cows; the expected effect of genetic selection for efficiency on the resulting phenotypic lactation profiles was also quantified.

\section{MATERIALS AND METHODS}

\section{Data}

Data were collected from the Animal and Grassland Research and Innovation Centre, Teagasc Moorepark, Fermoy, Co. Cork, Ireland, between the years 1995 to 2014, inclusive. Cows that participated in the current study originated from several controlled experiments that evaluated alternative grazing strategies, nutritional experiments, or strains of Holstein-Friesian animals; see O'Neill et al. (2013) for a full description of the database. The Holstein-Friesian animals consisted of differing genotypes originating from different populations (Kennedy et al., 2003; Buckley et al., 2007; McCarthy et al., 2007; Coleman et al., 2010). All experiments were performed on 2 adjacent research farms in southern Ireland (latitude $52^{\circ} 9^{\prime} \mathrm{N}$, longitude $8^{\circ} 16^{\prime} \mathrm{W}$ ). Grass DMI for each cow at pasture was periodically estimated using the n-alkane technique (Mayes et al., 1986).
Procedures used to gather and analyze fecal samples are described in Kennedy et al. (2008). All cows were offered a basal diet of grazed grass. Swards consisting primarily of perennial ryegrass (Lolium perenne) were managed under a rotational grazing system comparable to that detailed by Dillon et al. (1995). Some animals were supplemented with concentrate feed (depending on feeding protocol), varying from 0.89 to $4.0 \mathrm{~kg}$ of DM per cow daily, offered in equal feeds during each milking.

Cows were milked twice daily. Individual cow milk yield was recorded daily, whereas milk fat, protein, and lactose concentration was determined from successive morning and evening milk samples once per week using mid-infrared spectroscopy (FT6000, Foss, Hillerod, Denmark). Net energy requirement for lactation was calculated using the following formula according to Agabriel (2007):

$$
\begin{aligned}
\mathrm{NE}_{\mathrm{L}} & =(0.054 \times \mathrm{FC}+0.031 \times \mathrm{PC}+0.028 \times \mathrm{LC}-0.015) \\
& \times \text { milk kg},
\end{aligned}
$$

where $\mathrm{FC}$ is fat concentration (\%), $\mathrm{PC}$ is protein concentration (\%), and LC is lactose concentration (\%).

Individual animal BW was largely measured weekly following morning milking using electronic scales (TruTest Limited, Auckland, New Zealand). The scales were calibrated weekly against known loads. Body condition score on a scale of 1 (emaciated) to 5 (obese) was assessed by trained scorers every 2 to 3 weeks in increments of 0.25 (Edmonson et al., 1989). Cubic splines were fitted through individual BW and BCS test-day records as described elsewhere (Hurley et al., 2016).

Individual cow daily total DMI (i.e., grazed pasture DMI plus concentrate DMI) was available up to 8 times (average of 4.5 times) per lactation. Energy values of the pasture and concentrate were based on the French net energy system where 1 unité fourragère lait (UFL) is the net energy requirement for lactation equivalent to $1 \mathrm{~kg}$ of standard air-dried barley (Jarrige et al., 1986), equivalent to $7.11 \mathrm{MJ}$ of net energy or 11.85 MJ of ME. The offered herbage UFL concentration was calculated using the ADF and $\mathrm{CP}$ concentration, which were quantified in the laboratory (Jarrige, 1989). Concentrate UFL value was determined from the chemical composition of the feed. Where the net energy content of the offered herbage (UFL $/ \mathrm{kg}$ of DM) was not available (i.e., $10 \%$ of test-day records), the year-month average was assumed. Where the net energy content of the offered concentrate (UFL $/ \mathrm{kg}$ of DM) was not available (i.e., $20 \%$ of test-day records), the year-month average was assumed. The sum of pasture and concentrate $\mathrm{NE}_{\mathrm{I}}$ were used to define total net energy intake $\left(\mathbf{N E}_{\mathbf{I}}\right)$. 


\section{Data Editing}

Obvious data errors for BW, BCS, and the milk production traits (e.g., milk yield, fat concentration, protein concentration, and lactose concentration lower than $2 \mathrm{~kg}, 2 \%, 2 \%$, and $2 \%$, respectively) were discarded. Only data between 8 and 280 DIM were retained as limited data existed after 280 DIM. Parity was categorized as 1,2 , and $\geq 3$. Contemporary group of experimental treatment by test-date was defined for $\mathrm{NE}_{\mathrm{L}}, \mathrm{NE}_{\mathrm{I}}, \mathrm{BW}$, and BCS. Contemporary groups with less than 5 observations were discarded. Following edits, the final data set consisted of 95,455 test-day records from 2,505 lactations on 1,290 Holstein-Friesian cows; 8,199 individual feed intake measurements remained.

\section{Estimates of Energy Efficiency and Energy Balance}

Definitions of all traits have been previously described in detail by Hurley et al. (2016). Energy balance for each test day was calculated in accordance with the net energy system outlined by Jarrige (1989) and modified for Irish dairy systems by O'Mara (1996):

$$
\mathrm{EB}=\mathrm{NE}_{\mathrm{I}}-\Delta \mathrm{NE}-\mathrm{NE}_{\mathrm{L}}-\mathrm{NE}_{\mathrm{M}}-\mathrm{NE}_{\mathrm{P}},
$$

where $\mathrm{NE}_{\mathrm{I}}$ is daily net energy intake, $\Delta \mathrm{NE}$ is an adjustment of daily net energy intake for the proportion of concentrates in the diet, $\mathrm{NE}_{\mathrm{L}}$ is the daily net energy requirements for lactation, $\mathrm{NE}_{\mathrm{M}}$ is daily net energy requirements for maintenance calculated as $(1.4+0.6$ $\times \mathrm{BW} / 100) \times 1.2$, and $\mathrm{NE}_{\mathrm{P}}$ is daily net energy requirements for pregnancy where UFL requirements for the 6 th, 7 th, and 8th month of pregnancy were $0.9,1.6$, and 2.6, respectively (O’Mara, 1996).

Residual-Based Efficiency Traits. Residual energy intake (REI) for each day of the lactation was defined as the residuals from the regression of $\mathrm{NE}_{\mathrm{I}}$ on energy sinks and other energy sources as

$$
\begin{aligned}
& \mathrm{REI}=\mathrm{NE}_{\mathrm{I}}-\left[\mathrm{NE}_{\mathrm{L}}+\text { parity }+\sum_{i=1}^{2} \mathrm{DIM}^{i}+\mathrm{BW}^{0.75}+\mathrm{BCS}\right. \\
& +\mathrm{BW}^{0.75} \times \mathrm{BCS}+\Delta \mathrm{BW}^{+}+\Delta \mathrm{BW}^{-}+\Delta \mathrm{BCS}^{+}+\Delta \mathrm{BCS}^{-} \\
& \left.+\Delta \mathrm{BW}^{+} \times \mathrm{BCS}+\Delta \mathrm{BW}^{-} \times \mathrm{BCS}\right],
\end{aligned}
$$

where REI is daily residual energy intake, $\mathrm{NE}_{\mathrm{I}}$ is daily net energy intake, $\mathrm{NE}_{\mathrm{L}}$ is daily net energy requirements for lactation, parity $(1,2$, and $\geq 3), \sum_{i=1}^{2} \operatorname{DIM}^{i}$ is DIM included as a continuous variable with a linear $(i=1)$ and quadratic effect $(i=2)$, and $\mathrm{BW}^{0.75}$ is metabolic
$\mathrm{BW}$. The energy generated from a $1 \mathrm{~kg}$ loss in $\mathrm{BW}$ is less than the energy required for a 1-kg gain in $\mathrm{BW}$ (O'Mara, 1996); therefore, piecewise regression was applied to $\mathrm{BW}$ and $\mathrm{BCS}$ in the REI model where $\triangle \mathrm{BW}^{+}$ describes animals gaining $\mathrm{BW}$ and $\Delta \mathrm{BW}^{-}$describes animals losing $\mathrm{BW}$, whereas $\triangle \mathrm{BCS}^{+}$describes animals gaining $\mathrm{BCS}$ and $\triangle \mathrm{BCS}^{-}$describes animals losing BCS. No multicollinearity existed in the multiple regression model. The partial regression coefficients of the REI model are outlined in Hurley et al. (2016).

Analogous to residual gain in growing cattle (Koch et al., 1963), residual energy production (REP) for each day of lactation was derived from the residuals of a least squares regression model regressing net energy of lactation on $\mathrm{NE}_{\mathrm{I}}$ plus energy sinks and other energy sources, similar to that described by Coleman et al. (2010).

$$
\begin{aligned}
& \mathrm{REP}=\mathrm{NE}_{\mathrm{L}}-\left[\mathrm{NE}_{\mathrm{I}}+\text { parity }+\sum_{i=1}^{2} \mathrm{DIM}^{i}+\mathrm{BW}^{0.75}+\mathrm{BCS}\right. \\
& +\mathrm{BW}^{0.75} \times \mathrm{BCS}+\Delta \mathrm{BW}^{+}+\Delta \mathrm{BW}^{-}+\Delta \mathrm{BCS}^{+}+\Delta \mathrm{BCS}^{-} \\
& \left.+\Delta \mathrm{BW}^{+} \times \mathrm{BCS}+\Delta \mathrm{BW}^{-} \times \mathrm{BCS}\right]
\end{aligned}
$$

where $\mathrm{NE}_{\mathrm{L}}$ is daily net energy requirements for lactation, $\mathrm{NE}_{\mathrm{I}}$ is daily net energy intake, parity $(1,2$, and $\geq 3), \sum_{i=1}^{2} \mathrm{DIM}^{i}$ is DIM included as a continuous variable with a linear and quadratic effect, $\mathrm{BW}^{0.75}$ is metabolic $\mathrm{BW}, \Delta \mathrm{BW}^{+}$describes animals gaining $\mathrm{BW}, \Delta \mathrm{BW}^{-}$describes animals losing $\mathrm{BW}, \triangle \mathrm{BCS}^{+}$describes animals gaining $\mathrm{BCS}$, and $\triangle \mathrm{BCS}^{-}$describes animals losing BCS. No multicollinearity existed in the multiple regression model.

Analogous to residual intake and gain as defined by Berry and Crowley (2012) in growing cattle, residual intake and energy production (RIEP) was defined using both REI and REP, each standardized to have a variance of 1 :

$$
\mathrm{RIEP}=\widetilde{\mathrm{REP}}-\widetilde{\mathrm{REI}}
$$

where $\widetilde{\mathrm{REP}}$ is residual energy production standardized to a variance of 1 , and $\widehat{R E I}$ is residual energy intake standardized to a variance of 1 .

Ratio-Based Efficiency Traits. Energy conversion efficiency (ECE) for each day of lactation was defined as

$$
\mathrm{ECE}=\frac{\mathrm{NE}_{\mathrm{L}}}{\mathrm{NE}_{\mathrm{I}}}
$$


where $\mathrm{NE}_{\mathrm{L}}$ is daily net energy requirements for lactation, and $\mathrm{NE}_{\mathrm{I}}$ is daily net energy intake.

Metabolic efficiency (MEff) was defined as

$$
\mathrm{MEff}=\frac{\mathrm{NE}_{\mathrm{I}}-\mathrm{NE}_{\mathrm{L}}}{\mathrm{BW}^{0.75}}
$$

where $\mathrm{NE}_{\mathrm{I}}$ is daily net energy intake, $\mathrm{NE}_{\mathrm{L}}$ is net energy requirements for lactation, and $\mathrm{BW}^{0.75}$ is metabolic BW.

Feed to live-weight (FtW) was defined as

$$
\mathrm{FtW}=\frac{\mathrm{NE}_{\mathrm{I}}}{\mathrm{BW}^{0.75}},
$$

where $\mathrm{NE}_{\mathrm{I}}$ is daily net energy intake, and $\mathrm{BW}^{0.75}$ is metabolic BW.

Kleiber ratio (KR; Kleiber, 1961) in growing animals is defined as ADG divided by metabolic BW. An analogous Kleiber ratio trait in dairy cows was defined as

$$
\mathrm{KR}=\frac{\mathrm{NE}_{\mathrm{L}}}{\mathrm{BW}^{0.75}},
$$

where $\mathrm{NE}_{\mathrm{L}}$ is the net energy requirements for lactation, and $\mathrm{BW}^{0.75}$ is metabolic BW.

\section{Statistical Analysis}

Pearson correlation coefficients among traits were computed within each lactation stage, and the significance of the differences in the same pairwise correlations between parities and between lactation stages was determined using the Fisher r-to-z transformation. For the purpose of calculating the effect of stage of lactation and parity on the correlation among traits, stage of lactation was stratified into stages ( 8 to 90 DIM, from 91 to 180 DIM, and $>180$ DIM) and parity was defined as 1,2 , and $\geq 3$.

Linear mixed models in ASReml (Gilmour et al., 2009) were used to quantify the factors associated with each of the efficiency and production traits. Fixed effects treated as categorical variables were contemporary group, parity $(1,2$, and $\geq 3)$, stage of lactation (9 classes: 8-30, 31-60, .., 241-280 DIM), and the interaction between stage of lactation and parity. The proportion of Friesian and "other breeds, excluding Holstein" (Holstein was not included to avoid linear dependency in the model) were both treated as continuous variables. Within- and across-lactation animal permanent environmental effects were considered as random effects.
Supplementary analyses were undertaken to characterize the profiles of lactations divergent for mean lactation REI. Lactations were stratified into high and low (i.e., high or low 10\%) mean lactation REI, but a restriction was imposed that only lactations with a minimum of 3 REI values where one record had to be $<60$ DIM and another had to be >150 DIM; after edits, the data set contained 3,315 records from 622 lactations on 512 cows. A mixed model in ASReml (Gilmour et al., 2009) was then fitted with REI as the dependent variable and the same fixed effects as previously described; however, a within-lactation animal permanent environmental effect was the only random effect considered. The cow-lactation solutions for REI were stratified into 2 categories (i.e., high or low 10\%); in this instance "low" means closer to minus infinity (more efficient) and "high" means closer to plus infinity (less efficient). A mixed model with the fixed effects of contemporary group, parity $(1,2$, and $\geq 3)$, stage of lactation (9 classes: 8-30, 31-60, .., 241-280 DIM), and REI category ( $\mathrm{n}=3$; high, low, in between) was then used where the dependent variable was all of the performance and efficiency traits; an interaction between the REI category and lactation stage was also considered in the model as a fixed effect. Cow lactation was fitted as a random effect. Least squares means of the dependent variable for the high and low REI strata were compared.

\section{Genetic Evaluation}

A genetic evaluation was undertaken for $\mathrm{NE}_{\mathrm{I}}, \mathrm{ECE}$, REI, REP, and RIEP with the purpose of characterizing animals divergent in genetic merit for each of the 5 measures. All data used in the genetic evaluation were across an entire lactation (i.e., 8 to 280 DIM). A validation data set was generated which included animals with phenotypic records masked in the genetic evaluation. Cows in the validation data set were those that had phenotypic records in the years 2012 to 2014; all of their records were masked in the genetic evaluation including if the cow appeared in years earlier than 2012. A restriction was also imposed that cows in the validation data set had to have at least 3 paternal halfsibs with the respective phenotype in the years before 2012 and thus included in the genetic evaluation; the validation data set contained 947 test-day records from 249 cows. Data in the genetic evaluation consisted of 7,291 test-day records from 2,006 lactations on 1,094 cows. A pedigree file, of at least 4 generations (where available), was produced for all animals included in the study; 8 animals with no recorded sire were discarded. The average number of daughters per sire was 5.78. 
Table 1. Number of observations (N) and LSM (SE in parentheses) for EB and the efficiency and production traits for parity 1 , parity 2 , and parity $\geq 3$ cows

\begin{tabular}{|c|c|c|c|c|c|c|}
\hline Trait $^{1}$ & \multicolumn{2}{|c|}{ Parity 1} & \multicolumn{2}{|c|}{ Parity 2} & \multicolumn{2}{|c|}{ Parity $\geq 3$} \\
\hline$\overline{\mathrm{EB}, \mathrm{UFL} / \mathrm{d}}$ & 2,856 & $-0.38(0.10)^{\mathrm{a}}$ & 2,522 & $0.10(0.10)^{\mathrm{b}}$ & 2,314 & $-0.01(0.10)^{\mathrm{b}}$ \\
\hline MEff, UFL $/ \mathrm{kg}^{0.75}$ & 2,856 & $0.06(0.001)^{\mathrm{a}}$ & 2,522 & $0.06(0.001)^{\mathrm{b}}$ & 2,314 & $0.004(0.001)^{\mathrm{b}}$ \\
\hline FtW, UFL $/ \mathrm{kg}^{0.75}$ & 2,948 & $0.14(0.001)^{\mathrm{a}}$ & 2,632 & $0.15(0.001)^{b}$ & 2,401 & $0.15(0.001)^{\mathrm{b}}$ \\
\hline $\mathrm{KR}, \mathrm{UFL} / \mathrm{kg}^{0.75}$ & 31,237 & $0.08(0.001)^{\mathrm{a}}$ & 27,571 & $0.09(0.001)^{b}$ & 25,124 & $0.09(0.001)^{\mathrm{c}}$ \\
\hline $\mathrm{RIEP}, \mathrm{UFL} / \mathrm{d}$ & 2,852 & $0.10(0.07)^{\mathrm{a}}$ & 2,519 & $0.15(0.07)^{\mathrm{a}}$ & 2,308 & $-0.03(0.07)^{\mathrm{a}}$ \\
\hline $\mathrm{NE}_{\mathrm{I}}, \mathrm{UFL} / \mathrm{d}$ & 2,975 & $14.02(0.11)^{\mathrm{a}}$ & 2,689 & $16.76(0.11)^{\mathrm{b}}$ & 2,470 & $17.88(0.12)^{\mathrm{c}}$ \\
\hline $\mathrm{NE}_{\mathrm{L}}, \mathrm{UFL} / \mathrm{d}$ & 32,844 & $8.16(0.07)^{\mathrm{a}}$ & 29,298 & $9.86(0.08)^{\mathrm{b}}$ & 26,628 & $10.72(0.08)^{\mathrm{c}}$ \\
\hline $\mathrm{BW}^{0.75}, \mathrm{~kg}^{0.75}$ & 33,477 & $102.93(0.37)^{\mathrm{a}}$ & 29,472 & $110.80(0.38)^{\mathrm{b}}$ & 26,973 & $117.29(0.38)^{\mathrm{c}}$ \\
\hline BCS, scale 1 to 5 & 33,483 & $2.79(0.01)^{\mathrm{a}}$ & 29,608 & $2.74(0.01)^{\mathrm{b}}$ & 26,978 & $2.76(0.01)^{\mathrm{ab}}$ \\
\hline
\end{tabular}

${ }^{\mathrm{a}-\mathrm{C}}$ Values differing in superscript within rows are different $(P<0.05)$ from each other.

${ }^{1} \mathrm{~EB}=$ energy balance; $\mathrm{ECE}=$ energy conversion efficiency; MEff = metabolic efficiency; FtW $=$ feed to live-weight; KR $=\mathrm{Kleiber}$ ratio; REI $=$ residual energy intake; $\mathrm{REP}=$ residual energy production; RIEP $=$ residual intake and energy production; $\mathrm{NE}_{\mathrm{I}}=$ net energy intake; $\mathrm{BW}^{0.75}$ $=$ metabolic BW; UFL = unité fourragère lait.

Breeding values for $\mathrm{NE}_{\mathrm{I}}$, ECE, REI, REP, and RIEP were predicted for the 249 validation cows via their pedigree relationships using a mixed model in ASReml (Gilmour et al., 2009). The model fitted was the same as previously described; however, an animal additive genetic effect was added as a random term. The EBV for all of $\mathrm{NE}_{\mathrm{I}}$, ECE, REI, REP, and RIEP were stratified, within trait, into 3 groups of low, medium, and high; in this instance "low" means closer to minus infinity and "high" means closer to plus infinity. Subsequent to this, a mixed model with the fixed effects of contemporary group, parity $(1,2$, and $\geq 3)$, stage of lactation (9 classes: 8-30, 31-60, .., 241-280 DIM), and the stratum (i.e., high, average, low) of EBV for each of the 5 traits singly was used to determine the association between EBV for $\mathrm{NE}_{\mathrm{I}}$, ECE, REI, REP, and RIEP and phenotypic performance; an interaction between EBV stratum and lactation stage was also considered in the model as a fixed effect to determine if the association between EBV and phenotypic performance differed across stages of lactation. Animal lactation was fitted as a random effect. Least squares means of the high and low EBV for $\mathrm{NE}_{\mathrm{I}}$, ECE, REI, REP, and RIEP were compared.

\section{RESULTS}

\section{Factors Associated with the Efficiency and Production Traits}

The least squares means for EB, the efficiency and production traits for parity 1,2 , and $\geq 3$ cows are in Table 1. Least squares means for $\mathrm{NE}_{\mathrm{I}}, \mathrm{NE}_{\mathrm{L}}$, and $\mathrm{BW}^{0.75}$ across lactations are in Figure 1. Least squares means for EB and some efficiency traits across stages of lactation are in Figure 2. The mean, genetic standard deviation $\left(\sigma_{\mathrm{g}}\right)$, heritability, and repeatability for EB, the efficiency traits, and the production traits are in Table 2. Heritability estimates for the efficiency traits ranged from 0.05 (REI) to 0.21 (REP and KR). With the exception of REI, parity was associated $(P<0.05)$ with all efficiency and production traits. Stage of lactation, as well as the 2-way interaction of parity by stage of lactation, were associated $(P<0.001)$ with all efficiency and production traits. The observed effect of the 2-way interaction of parity by stage of lactation on the efficiency traits as well as the production traits was, however, biologically small (Figure 3 ). The proportion of Friesian in the cow was not associated $(P>0.05)$ with ECE, RIEP, MWT, and $\mathrm{NE}_{\mathrm{L}}$.

\section{Correlations}

Pearson correlations among the efficiency traits, the production traits, and EB for the entire data set are in Table 3. Residual energy intake was positively phenotypically correlated with $\mathrm{NE}_{\mathrm{I}}(0.72)$ and negatively phenotypically correlated with ECE (-0.56). Residual intake and energy production was positively phenotypically correlated with REP (0.84) but negatively phenotypically correlated with REI (-0.84). Phenotypic correlations between a given trait in one lactation stage with the same trait in another lactation stage are in Table 4; phenotypic correlations between a given trait in one parity with the same trait in another parity are in Table 5. With the exception of KR, correlations were all weak for the efficiency traits; in contrast, all production traits were moderately to strongly phenotypically 


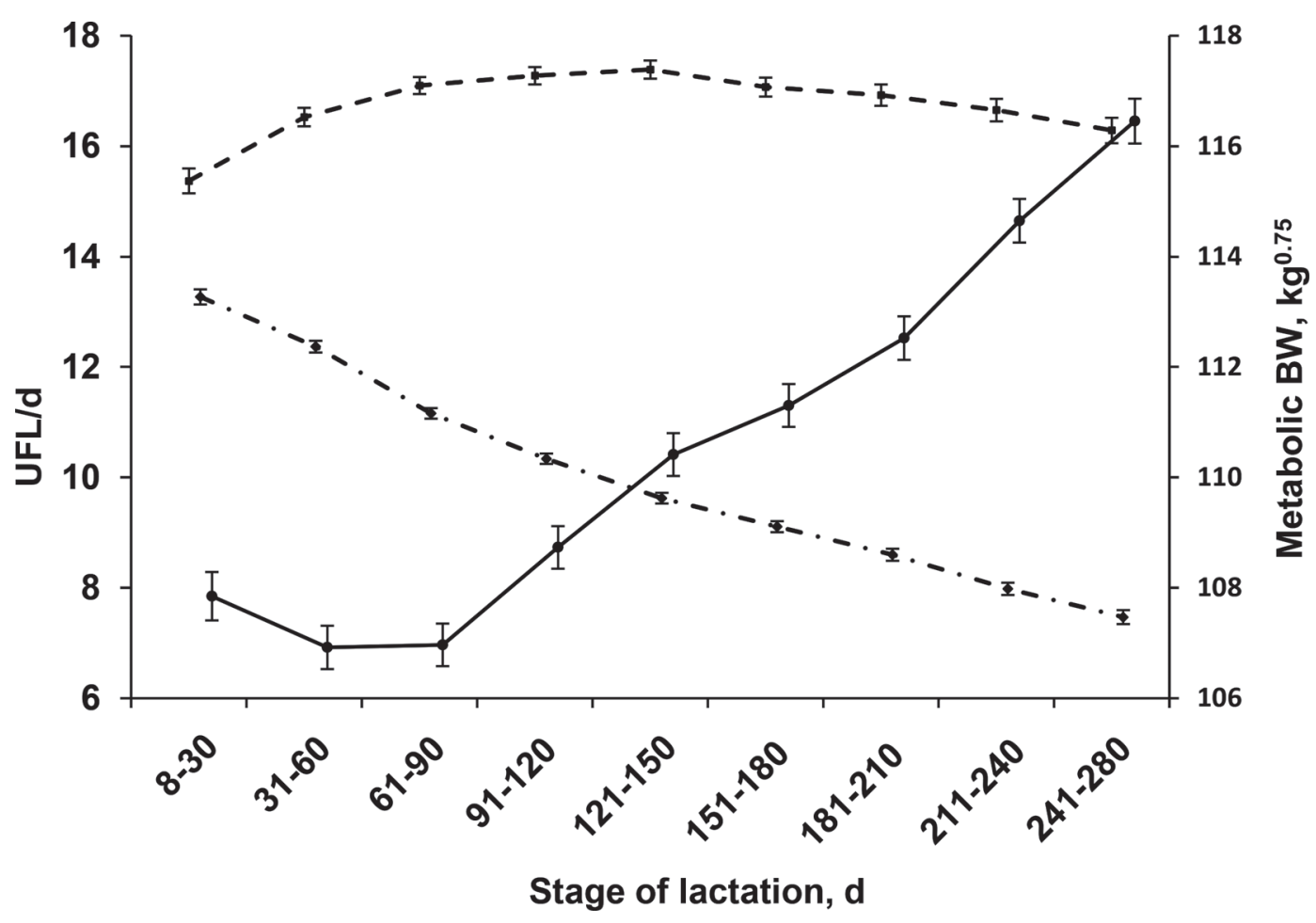

Figure 1. Least squares means for net energy intake [unité fourragère lait (UFL)/d; - - - - - ], NE $\mathrm{L}_{\mathrm{L}}\left(\mathrm{UFL} / \mathrm{d} ;-\right.$--- -.-), and metabolic BW $\left(\mathrm{kg}^{0.75}\right.$; - - ) across lactations. The error bars represent the SE per stage of lactation.

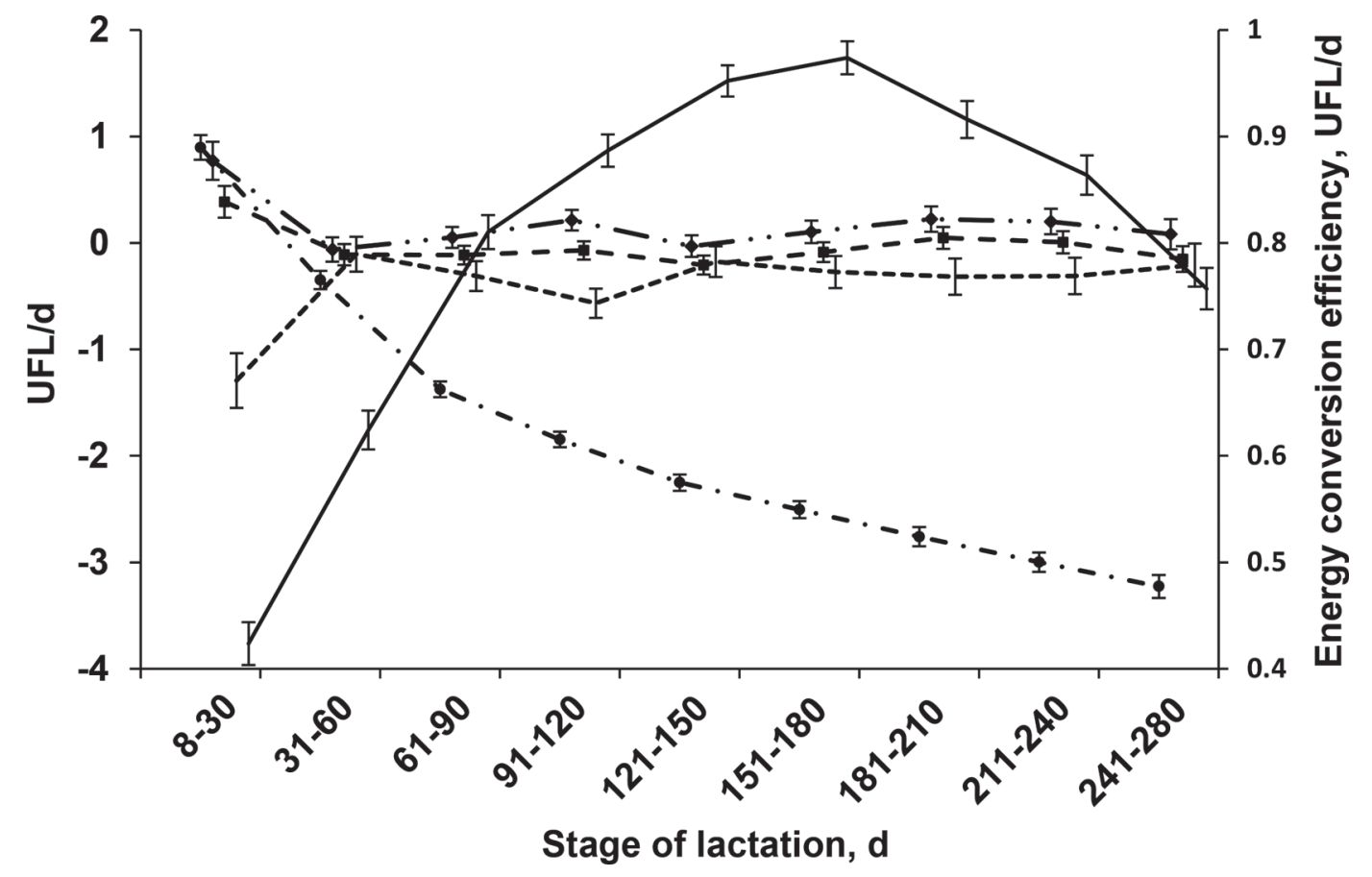

Figure 2. Least squares means for energy balance [unité fourragère lait (UFL)/d; - - ], energy conversion efficiency (---•-.-), residual energy intake (UFL/d; - - -), residual energy production (UFL/d; - - - - -), and residual intake and energy production (UFL/d; -..-- -..-) across lactations. The error bars represent the SE per stage of lactation. 


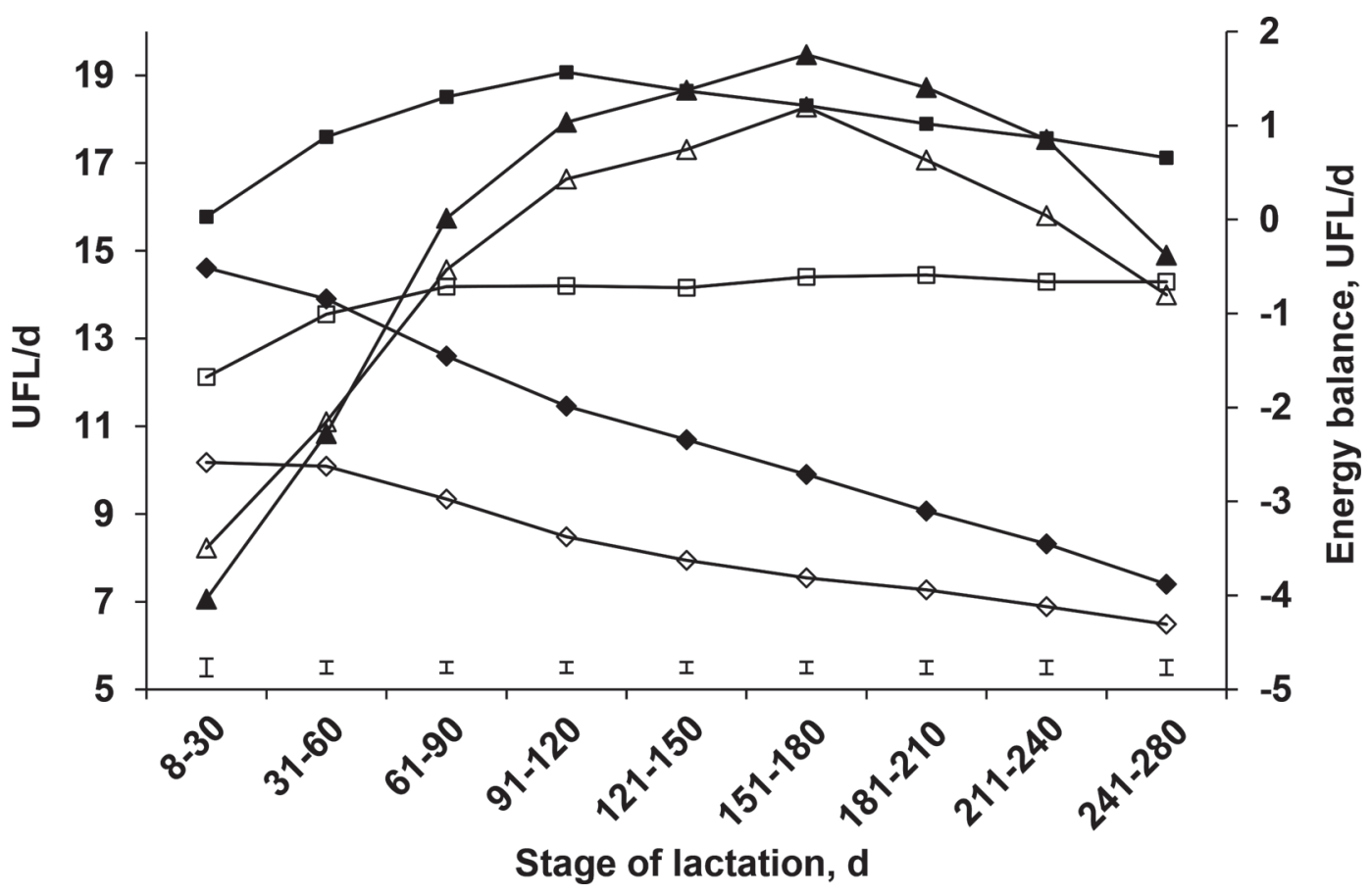

Figure 3. Least squares means across stage of lactation for net energy intake for parity 1 [unité fourragère lait (UFL)/d; - $\square-$ ] and parity $3(\mathrm{UFL} / \mathrm{d} ;--)$ cows, $\mathrm{NE}_{\mathrm{L}}$ for parity $1(\mathrm{UFL} / \mathrm{d} ;-\diamond-)$ ) and parity $3(\mathrm{UFL} / \mathrm{d} ;-\rightarrow-)$ cows, and energy balance for parity $1(\mathrm{UFL} / \mathrm{d} ;-\Delta-)$ and parity 3 (UFL/d; - - cows across lactation. The error bars represent the mean SE per stage of lactation.

correlated. Strong phenotypic correlations between BW in one lactation stage with BW in another lactation stage existed; strong phenotypic correlations also existed between $\mathrm{BW}$ in one parity with $\mathrm{BW}$ in another parity with phenotypic correlations never less than 0.82 .

The pairwise phenotypic correlations among the efficiency traits, $\mathrm{EB}$, and $\mathrm{NE}_{\mathrm{I}}$ within each stage of lactation (i.e., 8 to 90 DIM, 91 to 180 DIM, and $\geq 180$ DIM) by parity (i.e., 1,2 , and $\geq 3$ ) are in Table 6 . The phenotypic correlation between REI and EB strengthened
$(P<0.05)$ from early to mid lactation and was near unity from mid to late lactation irrespective of parity. A strong phenotypic correlation existed between REI and EB (0.89) for parity 3 or greater animals in early lactation, yet the same correlation was weaker $(P<$ $0.05)$ at the same stage of lactation in parity one animals (0.81). The phenotypic correlation between REP and ECE (0.59) in parity 1 early lactation animals was stronger $(P<0.05)$ at the same stage than animals in parity $2(0.65)$ and parity 3 or greater (0.66) animals.

Table 2. Number of records (N), mean, genetic SD $\left(\sigma_{g}\right)$, heritability (SE), and repeatability (SE) for EB and the efficiency and production traits

\begin{tabular}{|c|c|c|c|c|c|}
\hline Trait $^{1}$ & $\mathrm{~N}$ & Mean & $\sigma_{\mathrm{g}}$ & Heritability & Repeatability \\
\hline $\mathrm{EB}, \mathrm{UFL} / \mathrm{d}$ & 7,692 & 0.54 & 0.44 & $0.05(0.02)$ & $0.10(0.01)$ \\
\hline ECE & 7,829 & 0.60 & 0.02 & $0.11(0.02)$ & $0.16(0.01)$ \\
\hline MEff, UFL $/ \mathrm{kg}^{0.75}$ & 7,692 & 0.06 & 0.004 & $0.06(0.02)$ & $0.12(0.01)$ \\
\hline FtW, UFL $/ \mathrm{kg}^{0.75}$ & 7,981 & 0.15 & 0.01 & $0.09(0.02)$ & $0.23(0.02)$ \\
\hline $\mathrm{KR}, \mathrm{UFL} / \mathrm{kg}^{8.75}$ & 83,932 & 0.09 & 0.01 & $0.21(0.04)$ & $0.45(0.01)$ \\
\hline REI, UFL/d & 7,679 & 0.00 & 0.44 & $0.07(0.02)$ & $0.13(0.02)$ \\
\hline REP, UFL/d & 7,679 & 0.001 & 0.45 & $0.21(0.04)$ & $0.34(0.01)$ \\
\hline RIEP, UFL/d & 7,679 & 0.001 & 0.34 & $0.09(0.02)$ & $0.16(0.02)$ \\
\hline $\mathrm{NE}_{\mathrm{I}}, \mathrm{UFL} / \mathrm{d}$ & 8,134 & 16.55 & 0.80 & $0.10(0.03)$ & $0.28(0.02)$ \\
\hline $\mathrm{NE}_{\mathrm{L}}, \mathrm{UFL} / \mathrm{d}$ & 88,770 & 9.59 & 0.65 & $0.20(0.04)$ & $0.42(0.001)$ \\
\hline $\mathrm{BW}^{0.75}, \mathrm{~kg}^{0.75}$ & 89,922 & 110.21 & 6.92 & $0.17(0.05)$ & $0.92(0.01)$ \\
\hline BCS, scale 1 to 5 & 90,069 & 2.85 & 0.16 & $0.32(0.05)$ & $0.76(0.01)$ \\
\hline
\end{tabular}

${ }^{1} \mathrm{~EB}=$ energy balance; $\mathrm{ECE}$ = energy conversion efficiency; MEff = metabolic efficiency; FtW = feed to liveweight; $\mathrm{KR}=$ Kleiber ratio; REI = residual energy intake; $\mathrm{REP}=$ residual energy production; $\mathrm{RIEP}=$ residual intake and energy production; $\mathrm{NE}_{\mathrm{I}}=$ net energy intake; $\mathrm{BW}^{0.75}=$ metabolic $\mathrm{BW} ; \mathrm{UFL}=$ unité fourragère lait. 
Table 3. Phenotypic correlations among the efficiency traits, the production traits, and energy balance (EB) for the entire data set

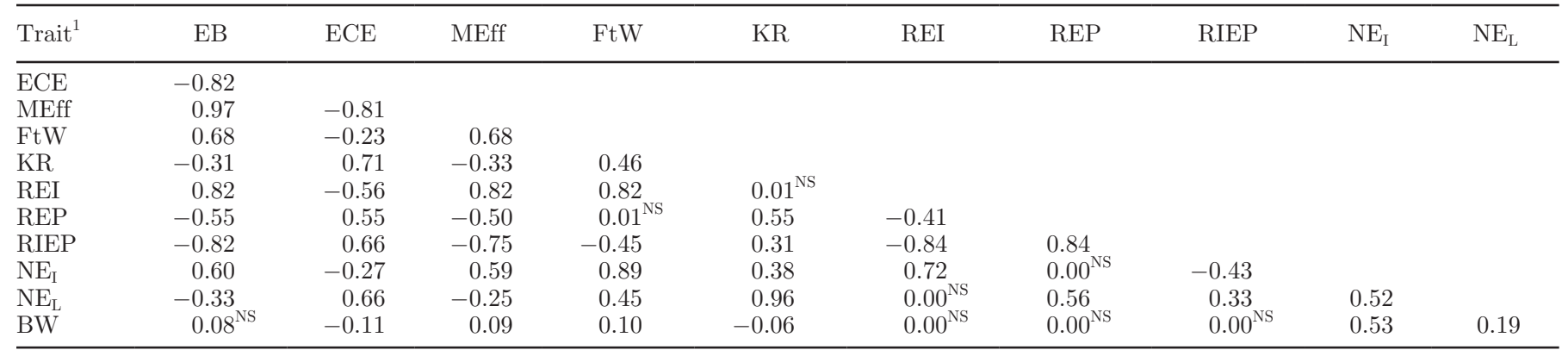

${ }^{1} \mathrm{ECE}=$ energy conversion efficiency; MEff = metabolic efficiency; FtW = feed to live-weight; KR = Kleiber ratio; REI = residual energy intake; $\mathrm{REP}=$ residual energy production; $\mathrm{RIEP}=$ residual intake and energy production; $\mathrm{NE}_{\mathrm{I}}=$ net energy intake.

${ }^{\mathrm{NS}}$ Correlation estimates do not differ $(P>0.05)$ from zero.

\section{Lactations Ranked on Residual Energy Intake and Energy Conversion Efficiency}

The association between EB, ECE, REI, and $\mathrm{NE}_{\mathrm{I}}$ and the REI category (i.e., high and low 10\%) was dependent on lactation stage. Figure 4 depicts the least squares means of EB, ECE, and REI of either the low $10 \%$ of lactations ( $\mathrm{n}=62$; most efficient) or high $10 \%$ of lactations ( $\mathrm{n}=62$; least efficient) ranked on REI. Lactations from animals ranked in the lowest (i.e., most negative) $10 \%$ on REI were consistently in negative EB and REI throughout lactation which differed $(P<$ $0.05)$ from the highest $10 \%$ of lactations ranked on REI where EB and REI were always positive (Figure 4).

Table 4. Phenotypic correlations* between observations within lactation stages for the efficiency traits, energy balance (EB), net energy intake $\left(\mathrm{NE}_{\mathrm{I}}\right)$, and $\mathrm{NE}_{\mathrm{L}}$

\begin{tabular}{|c|c|c|c|}
\hline \multirow[b]{2}{*}{ Trait $^{1}$} & \multirow[b]{2}{*}{ DIM stage } & \multicolumn{2}{|c|}{ Within lactation } \\
\hline & & 91-180 DIM & $>180 \mathrm{DIM}$ \\
\hline \multirow[t]{2}{*}{$\mathrm{EB}$} & $8-90$ & 0.11 & 0.22 \\
\hline & $91-180$ & & 0.09 \\
\hline \multirow[t]{2}{*}{ ECE } & $8-90$ & 0.16 & 0.13 \\
\hline & $91-180$ & & 0.04 \\
\hline \multirow[t]{2}{*}{ MEff } & $8-90$ & 0.08 & 0.17 \\
\hline & $91-180$ & & 0.07 \\
\hline \multirow[t]{2}{*}{ Ftw } & $8-90$ & 0.29 & 0.34 \\
\hline & $91-180$ & & 0.43 \\
\hline \multirow[t]{2}{*}{$\mathrm{KR}$} & 8-90 & 0.57 & 0.57 \\
\hline & $91-180$ & & 0.73 \\
\hline \multirow[t]{2}{*}{ REI } & $8-90$ & 0.19 & 0.23 \\
\hline & $91-180$ & & 0.12 \\
\hline \multirow[t]{2}{*}{ REP } & $8-90$ & 0.42 & 0.49 \\
\hline & $91-180$ & & 0.46 \\
\hline \multirow[t]{2}{*}{$\mathrm{NE}_{\mathrm{I}}$} & $8-90$ & 0.28 & 0.34 \\
\hline & $91-180$ & & 0.59 \\
\hline \multirow[t]{2}{*}{$\mathrm{NE}_{\mathrm{L}}$} & $8-90$ & 0.45 & 0.62 \\
\hline & $91-180$ & & 0.77 \\
\hline
\end{tabular}

${ }^{1} \mathrm{ECE}=$ energy conversion efficiency; MEff = metabolic efficiency; $\mathrm{FtW}=$ feed to live-weight; $\mathrm{KR}=$ Kleiber ratio; $\mathrm{REI}=$ residual energy intake; REP = residual energy production.

*All correlation estimates differed $(P<0.001)$ from 1 .
The lowest ranking lactations on REI ate, on average, 14.59 UFL per day, which was consistently less $(P<$ $0.05)$ when compared with the highest ranking lactations on REI, which ate, on average, 17.99 UFL per day. The lowest ranking lactations on REI produced, on average, 9.42 UFL per day (i.e., $\mathrm{NE}_{\mathrm{L}}$ ), which was less when compared with the highest ranking lactations on REI, which produced, on average, 9.69 UFL per day. No difference $(P>0.05)$ in $\mathrm{NE}_{\mathrm{L}}, \mathrm{BW}$, and $\mathrm{BCS}$ existed among the highest and lowest $10 \%$ of lactations ranked on REI. Where a cow is expected to remain in the herd, on average, 4 lactations over a typical 305-d lactation, then total $\mathrm{NE}_{\mathrm{I}}$ saved between lactations divergent on REI was 4,148 UFL; this saving is equivalent to three-

Table 5. Phenotypic correlations* between observations across parity for the efficiency traits, energy balance $(\mathrm{EB})$, net energy intake $\left(\mathrm{NE}_{\mathrm{I}}\right)$, and $\mathrm{NE}_{\mathrm{L}}$

\begin{tabular}{llcc}
\hline & & \multicolumn{2}{c}{ Across parity } \\
\cline { 3 - 4 } Trait $^{1}$ & Parity & Parity 2 & Parity $\geq 3$ \\
\hline EB & 1 & 0.22 & 0.07 \\
& 2 & & 0.06 \\
ECE & 2 & 0.18 & 0.02 \\
& 3 & & 0.03 \\
MEff & 2 & 0.23 & 0.04 \\
& 3 & & 0.02 \\
FtW & 2 & 0.35 & 0.27 \\
& 3 & & 0.47 \\
KR & 2 & 0.73 & 0.44 \\
& 3 & & 0.59 \\
REI & 1 & & 0.13 \\
& 2 & 0.55 & 0.23 \\
REP & 1 & & 0.40 \\
& 2 & 0.49 & 0.42 \\
NE & 1 & & 0.34 \\
& 2 & 0.78 & 0.44 \\
NE $_{\mathrm{L}}$ & 1 & & 0.51 \\
& 2 & & 0.63 \\
\hline
\end{tabular}

${ }^{1} \mathrm{ECE}=$ energy conversion efficiency; MEff $=$ metabolic efficiency; $\mathrm{FtW}=$ feed to live-weight; KR = Kleiber ratio; REI = residual energy intake; $\mathrm{REP}=$ residual energy production.

*All correlation estimates differed $(P<0.001)$ from 1. 


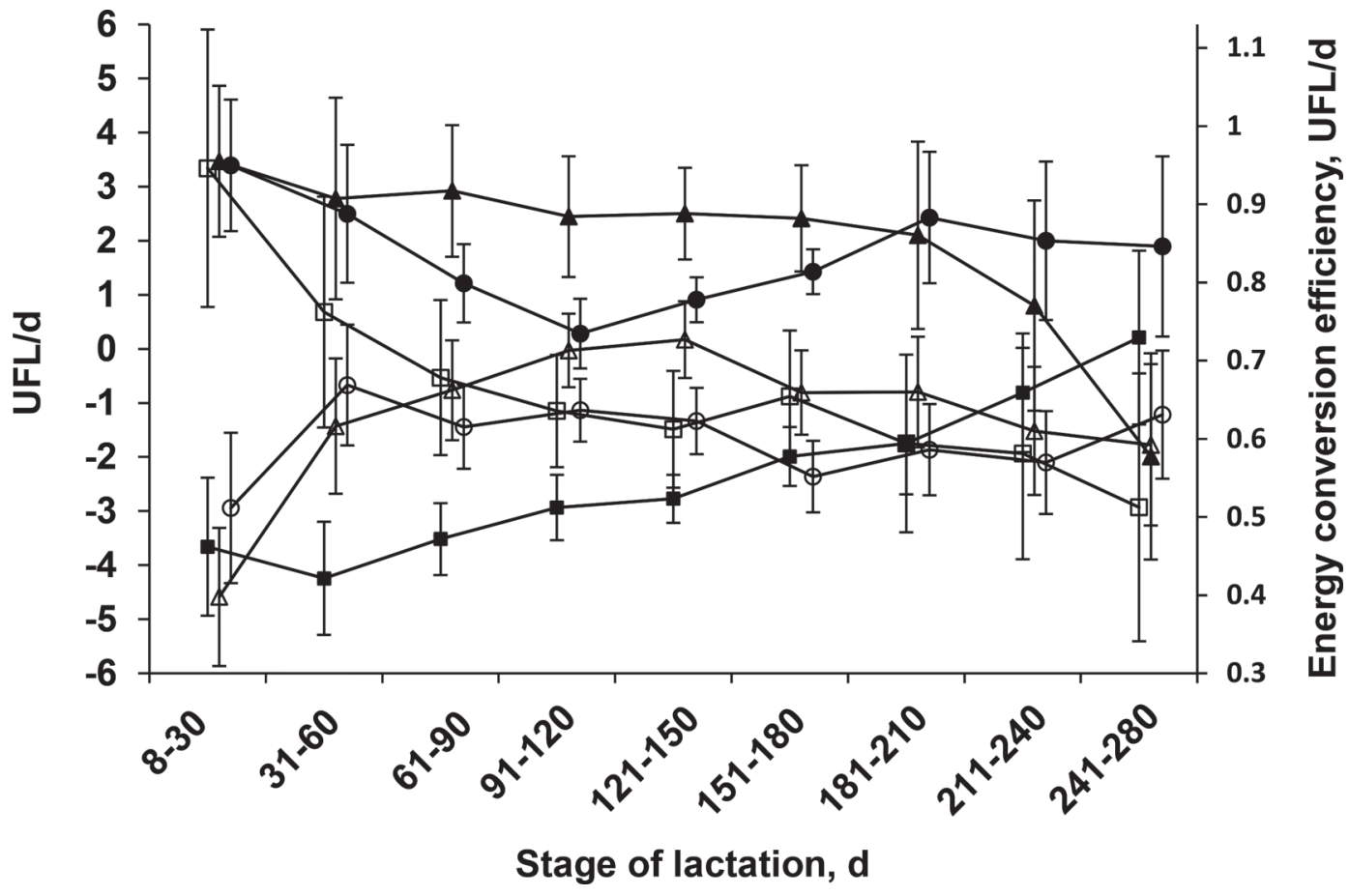

Figure 4. Least squares means across stage of lactation for the highest $(\mathrm{n}=62)$ and lowest $(\mathrm{n}=62) 10 \%$ of lactations for residual energy intake. Shaded symbols illustrate the highest $10 \%$ (i.e., inefficient lactations) of lactations, and unshaded symbols illustrate the lowest $10 \%$ (i.e., efficient lactations) of lactations for energy balance [unité fourragère lait (UFL)/d; $-\boldsymbol{\Delta} \Delta-$ ], energy conversion efficiency ( $-\square-$ ), and residual energy intake (UFL/d; - - ) . The errors bars represent SE.

quarters of the average feed intake of an Irish dairy cow for a typical 305-d lactation (Berry et al., 2006).

The association between EB, ECE, REI, NE , and BW and the ECE category (i.e., high and low 10\%) was dependent on lactation stage; however, the association between $\mathrm{NE}_{\mathrm{L}}$ and the ECE category (i.e., high and low 10\%) was not dependent on lactation stage. Supplementary Figure S1 (https://doi.org/10.3168/jds .2017-12841) depicts the least squares means of EB, ECE, and REI of either the lowest $10 \%$ of lactations (n $=62$; least efficient) and highest $10 \%$ of lactations $(\mathrm{n}=$ 62 ; most efficient) ranked on ECE. The highest ranking

Table 6. Phenotypic correlations among the efficiency traits, energy balance $(\mathrm{EB})$, and net energy intake $\left(\mathrm{NE}_{\mathrm{I}}\right)$ across lactation stages and parities $^{1}$

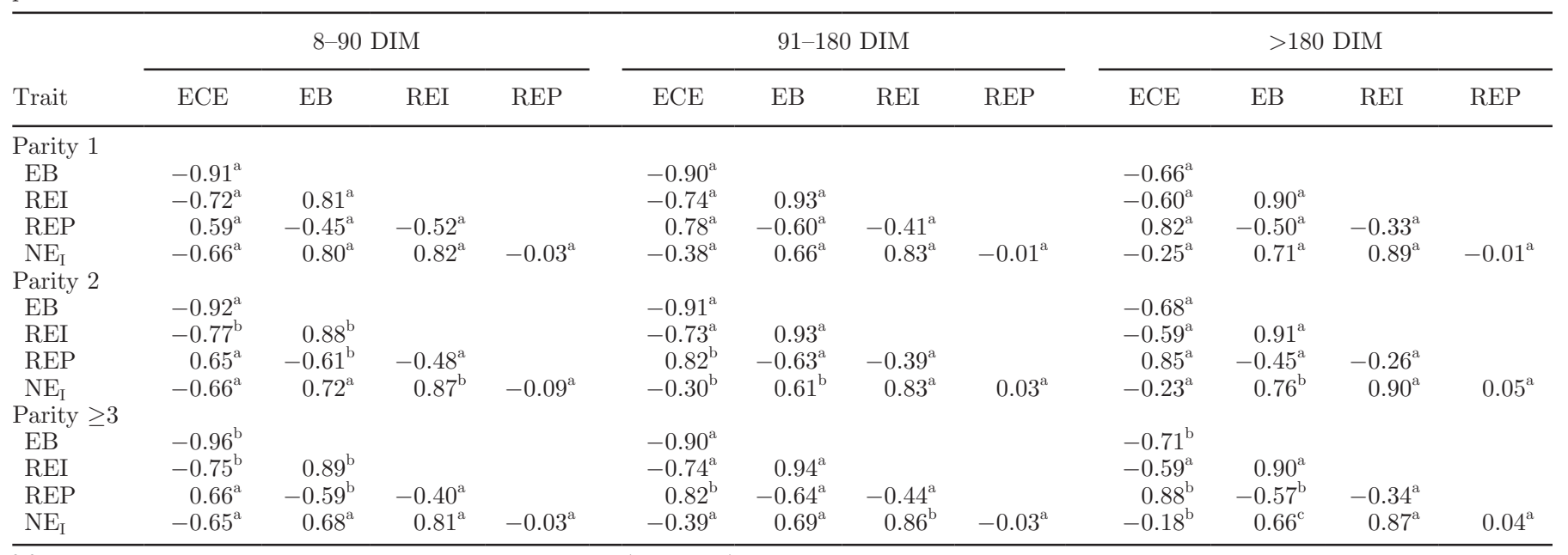

${ }^{\mathrm{a}-\mathrm{C}}$ Correlation estimates across parity within stage differ $(P<0.05)$ from each other.

${ }^{1} \mathrm{ECE}=$ energy conversion efficiency; REI = residual energy intake; REP = residual energy production. 
lactations on ECE (i.e., most efficient) consumed, on average, $15.66 \mathrm{UFL} / \mathrm{d}$, which was less when compared with the lowest ranking lactations on ECE, which, on average, consumed $16.62 \mathrm{UFL} / \mathrm{d}$. The highest ranking lactations on ECE were, on average, in more negative EB when compared with the lowest ranking lactations on ECE (Supplemental Figure S1; https://doi.org/10 .3168/jds.2017-12841).

\section{Effect of Genetic Selection for Feed Intake and Efficiency}

Least squares means, standard error of the difference, and significance of the efficiency traits and the production traits for cows divergent on EBV for ECE, REI, and REP are in Table 7. The association between EBV stratum and each of the feed efficiency and performance metrics did not differ $(P>0.05)$ by lactation stage; therefore, only the least squares means averaged across all stages of lactation are presented (Table 7). The stratum of cows genetically predisposed to have lower REI (i.e., more efficient) consumed 0.59 UFL/d $(P<0.01)$ less $\mathrm{NE}_{\mathrm{I}}$ and were in more negative $\mathrm{EB}$ $(P<0.001)$ than their lowest ranked contemporaries (Table 7). The EBV difference between the top and bottom ranked stratum of cows divergent on REP was $0.31 \mathrm{UFL} / \mathrm{d}(P<0.001)$. The top ranked EBV cows divergent on REP produced $0.65 \mathrm{UFL} / \mathrm{d}(P<0.0001)$ more $\mathrm{NE}_{\mathrm{L}}$ compared with the lowest ranked REP cows (Table 7).

Least squares means, standard error of the difference, and significance of the efficiency and production traits for cows divergent on $\mathrm{EBV}$ for $\mathrm{NE}_{\mathrm{I}}$ and RIEP are in Supplemental Table S1 (https://doi.org/10.3168/jds .2017-12841). The EBV difference between the top and bottom ranked cows divergent on $\mathrm{NE}_{\mathrm{I}}$ was $0.51 \mathrm{UFL} / \mathrm{d}$ $(P<0.001)$. The stratum of cows genetically predisposed to have greater $\mathrm{NE}_{\mathrm{I}}$ consumed $0.55 \mathrm{UFL} / \mathrm{d}(P<$ $0.01)$ more and were $2.81 \mathrm{~kg}^{0.75} / \mathrm{d}(P<0.001)$ heavier than their lowest ranked contemporaries (Supplemental Table S1; https://doi.org/10.3168/jds.2017-12841). Animals divergent on genetic merit for $\mathrm{NE}_{\mathrm{I}}$ did not differ $(P>0.05)$ in any of the efficiency traits. The EBV difference between the top and bottom ranked stratum of cows divergent on RIEP was $0.34 \mathrm{UFL} / \mathrm{d}$ $(P<0.001)$. The top ranked EBV cows divergent on RIEP consumed $0.92 \mathrm{UFL} / \mathrm{d}(P<0.0001)$ less $\mathrm{NE}_{\mathrm{I}}$, and produced $0.57 \mathrm{UFL} / \mathrm{d}(P<0.0001)$ more $\mathrm{NE}_{\mathrm{L}}$. Additionally, the top ranked stratum of cows divergent on RIEP had both greater ECE and REP $(P<0.0001)$, and had lower REI $(P<0.0001)$ compared with the lowest ranked RIEP cows (Supplemental Table S1; https://doi.org/10.3168/jds.2017-12841).

\section{DISCUSSION}

Many livestock industries including beef, swine, fish, and poultry either implicitly or explicitly include some component(s) of net feed efficiency in their breeding goals. The dairy industry, however, has been slow to explicitly include the feed intake and utilization complex in their breeding goals (Van der Werf, 2004; Berry and Crowley, 2013). This is primarily attributable to a lack of accurate feed intake data on commercial animals, but

Table 7. Least squares means, standard error of the difference (SED), and significance of the efficiency and production traits for cows divergent on ECE, REI, and REP

\begin{tabular}{|c|c|c|c|c|c|c|c|c|c|}
\hline Trait $^{1}$ & \multicolumn{3}{|c|}{$\mathrm{ECE}$} & \multicolumn{3}{|c|}{ REI } & \multicolumn{3}{|c|}{ REP } \\
\hline$\overline{\mathrm{EBV},{ }^{2} \mathrm{UFL} / \mathrm{d}}$ & 0.01 & -0.004 & $0.0004^{* * *}$ & 0.16 & -0.10 & $0.01^{* * *}$ & 0.19 & -0.12 & $0.01^{* * *}$ \\
\hline ECE & 0.57 & 0.55 & $0.01 *$ & 0.55 & 0.57 & 0.01 & 0.57 & 0.56 & 0.01 \\
\hline MEff, UFL $/ \mathrm{kg}^{0.75}$ & 0.07 & 0.07 & 0.002 & 0.08 & 0.07 & 0.002 & 0.07 & 0.07 & 0.002 \\
\hline FtW, UFL $/ \mathrm{kg}^{0.75}$ & 0.17 & 0.16 & $0.002^{*}$ & 0.16 & 0.16 & 0.002 & 0.17 & 0.16 & $0.002^{*}$ \\
\hline $\mathrm{REP}, \mathrm{UFL} / \mathrm{d}$ & 0.05 & -0.47 & $0.11^{* * *}$ & -0.26 & -0.18 & 0.11 & 0.02 & -0.64 & $0.10^{* *}$ \\
\hline RIEP, UFL/d & -0.44 & -0.77 & $0.13^{*}$ & -0.71 & -0.50 & 0.13 & -0.55 & -0.73 & 0.13 \\
\hline $\mathrm{NE}_{\mathrm{I}}, \mathrm{UFL} / \mathrm{d}$ & 17.09 & 17.28 & 0.21 & 17.38 & 16.79 & $0.20^{*}$ & 17.44 & 17.08 & $0.20^{*}$ \\
\hline $\mathrm{NE}_{\mathrm{L}}, \mathrm{UFL} / \mathrm{d}$ & 9.59 & 9.34 & $0.12^{*}$ & 9.48 & 9.40 & 0.11 & 9.68 & 9.03 & $0.11^{* * *}$ \\
\hline $\mathrm{BW}^{0.75}, \mathrm{~kg}^{0.75}$ & 103.11 & 107.32 & $0.61^{* *}$ & 104.25 & 103.89 & 0.60 & 105.68 & 107.74 & 0.59 \\
\hline BCS, scale 1 to 5 & 2.97 & 2.96 & 0.01 & 2.95 & 2.91 & 0.01 & 3.00 & 2.96 & 0.01 \\
\hline Reliability, \% & 11.01 & 12.03 & 0.01 & 9.85 & 8.54 & 0.01 & 8.85 & 7.54 & 0.01 \\
\hline
\end{tabular}

${ }^{1} \mathrm{~EB}=$ energy balance; $\mathrm{ECE}=$ energy conversion efficiency; MEff = metabolic efficiency; FtW $=$ feed to live-weight; KR $=$ Kleiber ratio; REI $=$ residual energy intake; $\mathrm{REP}=$ residual energy production; $\mathrm{RIEP}=$ residual intake and energy production; $\mathrm{NE}_{\mathrm{I}}=$ net energy intake; $\mathrm{UFL}=$ unité fourragère lait; $\mathrm{BW}^{0.75}=$ metabolic $\mathrm{BW}$.

${ }^{2} \mathrm{EBV}$ for animals segregated on ECE is unitless.

${ }^{*} P<0.05 ;{ }^{* *} P<0.01 ;{ }^{* * *} P<0.001$. 
also a lack of consistency in defining the most appropriate definition of the feed intake and utilization complex. With the expected volatility in future global milk price, one approach to maintaining resilience without necessarily sacrificing milk yield output is through enhanced feed efficiency. The objective of the present study was to investigate the inter- and intra-relationships within and among alternative feed efficiency metrics across different stages of lactation and parities; the expected effect of genetic selection for efficiency on the resulting phenotypic lactation profiles was also quantified.

Results from the present study indicate that sufficient genetic variability exists in the different efficiency traits investigated as evident by the genetic coefficient of variation, which ranged from $2.64 \%$ (REI) to $11.11 \%$ (KR). The fact that the (co)variation within and among the alternative efficiency metrics differ across parity and lactation stages suggests that not only are the efficiency traits all measuring different aspects of efficiency, but these relationships are not consistent across time. Nonetheless, the change in phenotypic (co) variances within and among traits for different life stages corroborate similar phenomena reported by Hurley et al. (2017) at a genetic level. This therefore suggests that the change in (co)variances across time is at least partly due to genetics. The phenotypic performance of cows genetically predisposed to have lower REI (i.e., more efficient) was that they consumed less $\mathrm{NE}_{\mathrm{I}}$ but were also in much greater negative EB, particularly in early lactation, relative to their genetically less efficient contemporaries. To the best of our knowledge, this is the first study that has illustrated the implications on phenotypic performance of selecting dairy cows genetically divergent for efficiency; results clearly demonstrated that phenotypic differences in feed intake and efficiency can be achieved through genetic selection.

\section{Correlations Within Traits}

Most studies investigating REI and other measures of efficiency in dairy cows assume that feed efficiency is phenotypically the same trait across lactation (Parke et al., 1999; Zamani et al., 2008; Manafiazar et al., 2016). Results from the present study, however, call this approach into question. In the present study, the fact that (correlations were less than unity) weak phenotypic correlations existed within almost all efficiency traits, both across parities and lactation stages, suggests that the efficiency traits need to be recorded across an entire lactation to monitor feed efficiency at a cow level. With the exception of $\mathrm{KR}$, the observed weak phenotypic correlation within each efficiency trait across time is in direct contrast to the generally strong within-trait phenotypic correlation for the production traits evalu- ated in the present study (Table 4 and 5 ). The observed weaker phenotypic correlations for the composite efficiency traits could be due to the underlying physiological changes the cow is undergoing throughout lactation (e.g., underlying milk compositional changes) and its effect on the partitioning of $\mathrm{NE}_{\mathrm{I}}$ into the different components at these lactation stages.

Namkoong (1985) stated that correlations of unity within the same component trait across environments can still result in re-ranking of cows for an index trait (e.g., REI) if the variance of the component traits in the environments differs. The strong phenotypic correlations between BW across parities and lactation stages, along with the similar variance for BW across time, suggests BW is unlikely to be contributing to the change in (co)variation of the index traits (i.e., traits that are a mathematical combination of other traits) such as REI, REP, and RIEP to change across time. In the present study, the moderate to strong phenotypic correlations and the differing variances for both $\mathrm{NE}_{\mathrm{L}}$ and $\mathrm{NE}_{\mathrm{I}}$ across time suggests, therefore, that $\mathrm{NE}_{\mathrm{L}}$ and $\mathrm{NE}_{\mathrm{I}}$ are more likely contributors to the observed reranking of the index traits across time.

\section{Correlations Between Traits}

Several studies have documented the inter-relationships among different measures of feed efficiency, but such estimates were based on lactation average performance and were not undertaken by lactation stage or by parity (Connor et al., 2013; Manafiazar et al., 2016; Manzanilla-Pech et al., 2016). Results from the present study suggest that although phenotypic correlations among the efficiency traits, $\mathrm{EB}$, and $\mathrm{NE}_{\mathrm{I}}$ estimated across the entire lactation (Table 3) are in general agreement with previous studies (Connor et al., 2013; Manafiazar et al., 2016), these pairwise correlations did in fact change both by stage of lactation and by parity. For example, the strong phenotypic correlation between REI and EB for early lactation cows in parity 3 or greater $(0.89)$ was weaker $(P<0.05)$ for parity 1 cows at the same lactation stage $(0.81)$. This phenomenon is probably due to primiparous cows also using the ingested energy for growth (Berry et al., 2004; Coffey et al., 2006).

The pairwise phenotypic correlation structure among the different traits investigated across the productive life generally varied more by stage of lactation than by parity. For example, the maximum difference in the correlation between EB and ECE across parities was never greater than 0.05 , but the maximum difference in the correlation between EB and ECE was 0.25 across lactation stages. This phenomenon suggests the physiological mechanisms controlling feed efficiency across 
lactation stages are much greater than those across parity. The phenotypic correlations between EB and ECE weakened from early to late lactation, suggesting improved efficiency was associated with animals in more negative EB. The strong negative phenotypic correlation between EB and ECE corroborates Spurlock et al. (2012) based on data from Holstein cows where $\mathrm{NE}_{\mathrm{I}}$ was measured for only the first half of lactation. As expected, REI and REP exhibited identical phenotypic correlations with their sum (RIEP). The strong phenotypic correlation between $\mathrm{NE}_{\mathrm{L}}$ with both ECE and KR suggests these traits were predominately influenced by $\mathrm{NE}_{\mathrm{L}}$. The strong phenotypic correlation between MEff and EB was expected as EB is close to a linearization of MEff (Hurley et al., 2016).

\section{Effect of Genetic Selection}

The heritability estimates for the majority of the efficiency traits in the present study were in general agreement with several other studies on either TMRor grass-fed lactating dairy cows (Ngwerume and Mao, 1992; Vallimont et al., 2011; Berry and Crowley, 2013). The heritability estimate for REI in the present study was nevertheless greater than the average of 0.04 reported by Berry and Crowley (2013) from a meta-analysis of the available literature on dairy and beef cows. Ample genetic variability existed for the different efficiency traits as evidenced in the present study by the coefficient of genetic variation, which was somewhat similar to the coefficient of genetic variation which existed for $\mathrm{NE}_{\mathrm{L}}$ (i.e., 6.74\%). Therefore, genetic progress in efficiency is achievable given this genetic variability as evident by the genetic gains achieved in milk production with a similar coefficient of genetic variation (Berry, 2008).

To the best of our knowledge, the present study is the first to quantify the effect on phenotypic performance of genetically selecting animals to be divergent for feed intake and efficiency based on parental average as would be the case in most breeding programs. Although response to selection for a trait can be predicted using selection index theory (Smith, 1936), accurate predictions require a large population of phenotyped animals to accurately estimate the necessary genetic parameters. Nonetheless, in the absence of precise estimates of the necessary genetic (co)variances, it is also possible to elucidate the response to selection through examination of phenotypic performance of animals divergent in genetic merit for the trait(s) of interest. Such a strategy could potentially be useful in lactating dairy cows where data are limited on some traits such as $\mathrm{NE}_{\mathrm{I}}$, and this strategy is often adopted in controlled studies for different performance traits (Coffey et al., 2003; Coleman et al., 2010).

Although, on average, the reliability of the lowest ranked cows $(\mathrm{n}=79)$ divergent on REI (i.e., most efficient) was low, the reliability of the mean of their EBV was $99 \%$. The phenotypic difference in REI between the high and low ranked cows divergent on REI was $0.38 \mathrm{UFL} / \mathrm{d}$, which is slightly larger than the expectation of $0.26 \mathrm{UFL} / \mathrm{d}$ based on their mean EBV difference for REI. The difference in REI between the high and low ranked cows divergent on REI represented $2.30 \%$ of mean $\mathrm{NE}_{\mathrm{I}}$ (i.e., $16.55 \mathrm{UFL} / \mathrm{d}$ ), whereas the difference in EBV between the high and low ranked cows divergent on REI was less, representing $1.57 \%$ of mean $\mathrm{NE}_{\mathrm{I}}$. This clearly illustrates that the variability in REI is small, even though the cows on trial were an unselected population but represented considerable genetic diversity with the Holstein-Friesians used originating from many different countries (McCarthy et al., 2007; Coleman et al., 2010). Nonetheless, there is scope for selecting on REI as evidenced by the genetic standard deviation (0.44 UFL/d) and the observed response to selection.

The phenotypic difference in $\mathrm{NE}_{\mathrm{I}}$ between the high and low ranked cows divergent on REI was 0.59 UFL/d. Therefore, assuming a cow remains in the herd for, on average, 4 lactations, over $365 \mathrm{~d}$, this translates to an estimated saving of $€ 67.19$ (assuming a cost of $€ 0.078 /$ UFL; Finneran et al., 2010). The potential extra revenue generated is close to $€ 17$ million over a 365 -d period per million dairy cows. The value of REI has previously been quantified in Australia using selection index theory; results illustrate that residual feed intake contributed approximately $3 \%$ per year of the genetic gain for extra profit, which was documented to be worth an estimated AUS $\$ 0.55 \mathrm{M}$ to the industry per year (Gonzalez-Recio et al., 2014). Cows ranked divergent on REI were also more efficient with higher ECE compared with their less efficient counterparts, although no differences in MEff, FtW, and KR existed between both groups.

Although many studies (Herd and Arthur, 2009; Crowley et al., 2010) proposed selecting for more negative REI (i.e., more efficient), results from the present study suggest that selection on negative REI alone will result in cows that are in greater negative EB, especially in early lactation. The implication of negative EB on health and fitness traits, including fertility, has been well documented (Beam and Butler, 1999; Collard et al., 2000; De Vries and Veerkamp, 2000). Nonetheless, such repercussions of negative EB do not imply that selection for negative REI should not be practiced, but instead should be undertaken within the framework of a balanced breeding objective that includes traits such 
as reproduction and health (Berry and Crowley, 2013). Moreover, (some of) the strong relationship observed in the present study between REI and EB could simply be a statistical artifact of the mathematical definition of both REI and EB in the present study; the use of many of same parameters in the definition of both traits imply a part-whole relationship, thus contributing to a statistical relationship. Whether the relationships heretofore reported between EB with both health and fertility (Beam and Butler, 1999; Collard et al., 2000; De Vries and Veerkamp, 2000) also exist for REI remains largely unknown.

The phenotypic difference in REP between the high and low ranked cows divergent on REP was $0.66 \mathrm{UFL} / \mathrm{d}$, which is double the expectation of $0.31 \mathrm{UFL} / \mathrm{d}$ based on the mean difference in EBV for REP between the divergent cows. The difference in REP between the high and low ranked cows divergent on REP represented $6.78 \%$ of mean $\mathrm{NE}_{\mathrm{L}}$ (i.e., 9.59 UFL/d), whereas the difference in EBV between the high and low ranked cows divergent on REP represented $3.23 \%$ of mean $\mathrm{NE}_{\mathrm{L}}$. These results suggest considerably greater variability exists in REP compared with REI, which was substantiated by the coefficient of genetic variation for REP (i.e., 4.73\%) being almost twice as large as the coefficient of genetic variation for REI (i.e., 2.64\%).

\section{CONCLUSIONS}

Results from the present study suggest that caution should be demonstrated when accessing the inter- and intra-relationships among alternative feed efficiency metrics on a per lactation basis because these do vary both across parities and across lactation stages, or at the very least when presenting such correlations, from where the data originates should be made clear. This is the first study to comprehensively describe the implications on phenotypic performance from lactating dairy cows genetically diverse for efficiency measures. Results clearly show that phenotypic differences in feed intake and efficiency can be achieved through genetic selection; of course the results reported within are only applicable to the population used in the present study, which was based on an extensive production system where the basal cow diet consisted predominantly of in situ grazed grass. Given the need to increase the production of several important agricultural commodities, including milk, REI, or REP could offer possible effective solutions to increase production efficiency. Nonetheless, genetic correlations with the feed intake and utilization complex with both reproduction and health traits need to be estimated before possible consideration in any breeding program.

\section{ACKNOWLEDGMENTS}

Funding from the Irish Department of Agriculture, Food and Marine (Dublin, Ireland) Research Stimulus Fund project Genetics of cost production traits (GENCOST), and funding from the Horizon 2020 Marie Curie project International Research Staff Exchange Scheme Global cooperation to develop next generation whole genome sequence selection tools for novel traits (SEQSEL) are greatly appreciated.

\section{REFERENCES}

Agabriel, J. 2007. Alimentation des bovins, ovins et caprins: besoins des animaux, valeurs des aliments: Tables INRA 2007. Editions Quae, Paris, France.

Beam, S. W., and W. R. Butler. 1999. Effects of energy balance on follicular development and first ovulation in postpartum dairy cows. J. Reprod. Fertil. Suppl. 54:411-424.

Berry, D. P. 2008. Genetics-A tool to improve productivity and profitability. Int. J. Dairy Technol. 61:30-35.

Berry, D. P., F. Buckley, P. Dillon, R. D. Evans, and R. F. Veerkamp. 2004. Genetic relationships among linear type traits, milk yield, body weight, fertility and somatic cell count in primiparous dairy cows. Ir. J. Agric. Food Res. 43:161-176.

Berry, D. P., and J. J. Crowley. 2012. Residual intake and body weight gain: A new measure of efficiency in growing cattle. J. Anim. Sci. 90:109-115.

Berry, D. P., and J. J. Crowley. 2013. Genetics of feed efficiency in dairy and beef cattle. J. Anim. Sci. 91:1594-1613.

Berry, D. P., R. F. Veerkamp, and P. Dillon. 2006. Phenotypic profiles for body weight, body condition score, energy intake, and energy balance across different parities and concentrate feeding levels. Livest. Sci. 104:1-12.

Buckley, F., B. Horan, N. Lopez-Villalobos, and P. Dillon. 2007. Milk production efficiency of varying dairy cow genotypes under grazing conditions. Pages 74-83 in Meeting the Challenges for PastureBased Dairying. Proc. 3rd Dairy Sci. Symp., University of Melbourne, Victoria, Australia.

Cahaner, A., and P. B. Siegel. 1986. Evaluation of industry breeding programs for meat-type chickens and turkeys. 3rd World Congr. Gene. Appl. Livestock Prod. 10:337-346.

Coffey, M. P., J. Hickey, and S. Brotherstone. 2006. Genetic aspects of growth of Holstein-Friesian dairy cows from birth to maturity. J. Dairy Sci. 89:322-329.

Coffey, M. P., G. Simm, W. G. Hill, and S. Brotherstone. 2003. Genetic evaluations of dairy bulls for daughter energy balance profiles using linear type scores and body condition score analyzed using random regression. J. Dairy Sci. 86:2205-2212.

Coleman, J., D. P. Berry, K. M. Pierce, A. Brennan, and B. Horan. 2010. Dry matter intake and feed efficiency profiles of 3 genotypes of Holstein-Friesian within pasture-based systems of milk production. J. Dairy Sci. 93:4318-4331.

Collard, B. L., P. J. Boettcher, J. C. M. Dekkers, D. Petitclerc, and L. R. Schaeffer. 2000. Relationships between energy balance and health traits of dairy cattle in early lactation. J. Dairy Sci. 83:2683-2690.

Connor, E. E., J. L. Hutchison, H. D. Norman, K. M. Olson, C. P. Van Tassell, J. M. Leith, and R. Baldwin. 2013. Use of residual feed intake in Holsteins during early lactation shows potential to improve feed efficiency through genetic selection. J. Anim. Sci. 91:3978-3988.

Crowley, J. J., M. McGee, D. A. Kenny, D. H. Crews, R. D. Evans, and D. P. Berry. 2010. Phenotypic and genetic parameters for different measures of feed efficiency in different breeds of Irish performancetested beef bulls. J. Anim. Sci. 88:885-894. 
De Vries, M., and R. F. Veerkamp. 2000. Energy balance of dairy cattle in relation to milk production variables and fertility. J. Dairy Sci. 83:62-69.

Dillon, P., S. Crosse, G. Stakelum, and F. Flynn. 1995. The effect of calving date and stocking rate on the performance of springcalving dairy cows. Grass Forage Sci. 50:286-299.

Edmonson, A. J., I. J. Lean, L. D. Weaver, T. Farver, and G. Webster. 1989. A body condition scoring chart for Holstein dairy cows. J. Dairy Sci. 72:68-78.

Finneran, E., P. Crosson, P. O'kiely, L. Shalloo, D. Forristal, and M. Wallace. 2010. Simulation modelling of the cost of producing and utilising feeds for ruminants on Irish farms. J. Farm Manage. 14:95-116.

Gilmour, A. R., B. Gogel, B. Cullis, R. Thompson, and D. Butler. 2009. ASReml user guide release 3.0. VSN International Ltd. Hemel Hempstead, UK.

Gonzalez-Recio, O., J. E. Pryce, M. Haile-Mariam, and B. J. Hayes. 2014. Incorporating heifer feed efficiency in the Australian selection index using genomic selection. J. Dairy Sci. 97:3883-3893.

Havenstein, G. B., P. R. Ferket, and M. A. Qureshi. 2003. Growth, livability, and feed conversion of 1957 versus 2001 broilers when fed representative 1957 and 2001 broiler diets. Poult. Sci. 82:15001508.

Havenstein, G. B., P. R. Ferket, S. E. Scheideler, and B. T. Larson. 1994. Growth, livability, and feed conversion of 1957 vs 1991 broilers when fed typical 1957 and 1991 broiler diets. Poult. Sci. 73:1785-1794

Herd, R. M., and P. F. Arthur. 2009. Physiological basis for residual feed intake. J. Anim. Sci. 87(14 Suppl.):E64-E71.

Hurley, A. M., N. López-Villalobos, S. McParland, E. Kennedy, E. Lewis, M. O'Donovan, J. L. Burke, and D. P. Berry. 2016. Interrelationships among alternative definitions of feed efficiency in grazing lactating dairy cows. J. Dairy Sci. 99:468-479.

Hurley, A. M., N. López-Villalobos, S. McParland, E. Kennedy, E. Lewis, M. O'Donovan, J. L. Burke, and D. P. Berry. 2017. Genetics of alternative definitions of feed efficiency in grazing lactating dairy cows. J. Dairy Sci. 100:5501-5514.

Jarrige, R. 1989. Ruminant Nutrition: Recommended Allowances and Feed Tables. Libbey, London, UK.

Jarrige, R., C. Demarquilly, J. P. Dulphy, A. Hoden, J. Robelin, C. Beranger, Y. Geay, M. Journet, C. Malterre, D. Micol, and M. Petit. 1986. The INRA "fill unit" system for predicting the voluntary intake of forage-based diets in ruminants: A review. J. Anim. Sci. 63:1737-1758

Kennedy, E., M. O'Donovan, L. Delaby, and F. P. O'Mara. 2008. Effect of herbage allowance and concentrate supplementation on dry matter intake, milk production and energy balance of early lactating dairy cows. Livest. Sci. 117:275-286.

Kennedy, J., P. Dillon, P. Faverdin, L. Delaby, G. Stakelum, and M Rath. 2003. Effect of genetic merit and concentrate supplementation on grass intake and milk production with Holstein-Friesian dairy cows. J. Dairy Sci. 86:610-621.

Kleiber, M. 1961. The Fire of Life. An Introduction to Animal Energetics. Wiley, New York, NY.

Koch, R. M., L. A. Swiger, D. Chambers, and K. E. Gregory. 1963. Efficiency of feed use in beef cattle. J. Anim. Sci. 22:486-494.

Leip, A., G. Billen, J. Garnier, B. Grizzetti, L. Lassaletta, S. Reis, D. Simpson, M. A. Sutton, W. De Vries, F. Weiss, and H. Westhoek. 2015. Impacts of European livestock production: nitrogen, sulphur, phosphorus and greenhouse gas emissions, land-use, water eutrophication and biodiversity. Environ. Res. Lett. 10:115004.

Losinger, W. C. 1998. Feed-conversion ratio of finisher pigs in the USA. Prev. Vet. Med. 36:287-305.

Manafiazar, G., L. Goonewardene, F. Miglior, D. H. Crews, J. A. Basarab, E. Okine, and Z. Wang. 2016. Genetic and phenotypic correlations among feed efficiency, production and selected conformation traits in dairy cows. Animal 10:381-389.

Manzanilla-Pech, C. I. V., R. F. Veerkamp, R. Tempelman, M. van Pelt, K. Weigel, M. VandeHaar, T. Lawlor, D. Spurlock, L. Armentano, and C. Staples. 2016. Genetic parameters between feedintake-related traits and conformation in 2 separate dairy populations-the Netherlands and United States. J. Dairy Sci. 99:443-457.

Mayes, R. W., C. S. Lamb, and P. M. Colgrove. 1986. The use of dosed and herbage n-alkanes as markers for the determination of herbage intake. J. Agric. Sci. 107:1-170.

McCarthy, S., B. Horan, M. Rath, M. Linnane, P. O'Connor, and P. Dillon. 2007. The influence of strain of Holstein-Friesian dairy cow and pasture-based feeding system on grazing behaviour, intake and milk production. Grass Forage Sci. 62:13-26.

Namkoong, G. 1985. The influence of composite traits on genotype by environment relations. Theor. Appl. Genet. 70:315-317.

Ngwerume, F., and I. L. Mao. 1992. Estimation of residual energyintake for lactating cows using an animal-model. J. Dairy Sci. $75: 2283-2287$

O'Mara, F. 1996. A net energy system for cattle and sheep. University College Dublin, Department of Animal Science and Production, Dublin.

O'Neill, B., E. Lewis, M. O'Donovan, L. Shalloo, F. Mulligan, T. Boland, and R. Delagarde. 2013. Evaluation of the GrazeIn model of grass dry-matter intake and milk production prediction for dairy cows in temperate grass-based production systems. 1-Sward characteristics and grazing management factors. Grass Forage Sci. 68:504-523.

Parke, P., B. W. Kennedy, J. C. M. Dekkers, R. K. Moore, and L. Jairath. 1999. Genetic and phenotypic parameter estimates between production, feed intake, feed efficiency, body weight and linear type traits in first lactation Holsteins. J. Anim. Sci. 79:425-431.

Sherwood, D. H. 1977. Modern broiler feeds and strains: What two decades of improvement have done. Feedstuffs 49:70.

Smith, H. F. 1936. A discriminant function for plant selection. Ann. Eugen. 7:240-250.

Spurlock, D. M., J. C. M. Dekkers, R. Fernando, D. A. Koltes, and A Wolc. 2012. Genetic parameters for energy balance, feed efficiency, and related traits in Holstein cattle. J. Dairy Sci. 95:5393-5402.

Vallimont, J. E., C. D. Dechow, J. M. Daubert, M. W. Dekleva, J. W Blum, C. M. Barlieb, W. Liu, G. A. Varga, A. J. Heinrichs, and C. R. Baumrucker. 2011. Short communication: Heritability of gross feed efficiency and associations with yield, intake, residual intake, body weight, and body condition score in 11 commercial Pennsylvania tie stalls. J. Dairy Sci. 94:2108-2113.

Van der Werf, J. H. J. 2004. Is it useful to define residual feed intake as a trait in animal breeding programs? Anim. Prod. Sci. 44:405-409.

Zamani, P., S. R. M. Ashtiani, and H. Mohammadi. 2008. Genetic parameters of residual energy intake and its correlations with other traits in Holstein dairy cattle. Turk. J. Vet. Anim. Sci. 32:255-261.

Zuidhof, M. J., B. L. Schneider, V. L. Carney, D. R. Korver, and F. E. Robinson. 2014. Growth, efficiency, and yield of commercial broilers from 1957, 1978, and 2005. Poult. Sci. 93:2970-2982. 